\title{
Effect of van der Waals and three body interactions on the lattice dynamics of Ionic crystals: an application to SrO
}

\author{
R. K. Trivedi ${ }^{1}$, K. K. Mishra ${ }^{1,3 *}$, S. K. Upadhyay ${ }^{2}$, G. K. Upadhyay ${ }^{3}$ \\ K. S. Upadhyaya ${ }^{1}$ \\ ${ }^{I}$ Dept. of Physics, Nehru Gram Bharati University, Kotwa, Jamunipur, Jhusi, Allahabad-221505 \\ ${ }^{2}$ Dept. of Applied Physics, Vishveshwarya Institute of Engineering and Technology, Greater Noida-203207 \\ ${ }^{3}$ Landmark Technical Campus, Didauli, National Highway-24,Amroha, J.P.Nagar-244222, U.P.
}

\begin{abstract}
A new model of lattice dynamics has been developed by incorporating the effect of van der Waals interactions and three-body interactions in the frame work of rigid shell model where short range interactions are effective upto the second neighbour. This model has been applied to study the complete lattice dynamics of strontium oxide ( $\mathrm{SrO}$ ). A good agreement has been obtained between theory and experiment.
\end{abstract}

Keywords: Lattice dynamics, Phonon dispersion curves, Debye temperature, two phonon IR and Raman Spectra, An harmonic elastic constants, combined density of states, strontium oxide.

\section{INTRODUCTION}

The present paper is an outcome to the efforts devoted to carry out a systematic theoretical investigation of the phonon dispersion, Debye temperature variation, two phonon density of states and third and fourth order elastic constants and present derivatives of $\mathrm{SrO}$. The inputs for undertaking this work was gained from the fact that the oxides of alkaline earths form an important class of ionic solid with $\mathrm{NaCl}$ structure which possess peculiar elastic and dielectric properties. This is self evident from the fact that the experimental elastic constants obey the strange relation $\left(C_{44} \approx 2 C_{12}\right)$ for $\mathrm{MgO}$. Also the static and high frequency dielectric constants for these solids have much higher values than the alkali halides. The lattice dynamic of these solids has been extensively studied both theoretically and experimentally during the recent past. The experimental measurements have provided a wealth of data on their phonon dispersion, elastic and dielectric properties. In order to interpret them, several lattice dynamical models have been use namely, the rigid ion model $(R I M)$ [1], the rigid shell model (RSM) [2] and some other variations of the shell model [3 and 4], and however, none of them has been able to predict the experimental results very well. The strange features in the nature and physical properties of the alkaline earth oxides $(\mathrm{MgO}, \mathrm{CaO}, \mathrm{SrO}$ and $\mathrm{BaO})$ have given an increased interest in study of their lattice dynamics. Although, the dispersion relations deduced from the neutron scattering techniques are available for the all of the them [5-9] and their interpretations by means of theoretical models [10-16] have also met with great success, still, the studies of lattice dynamics of $\mathrm{SrO}$ has been problem yet to be discussed.

In order to explain the lattice vibrational behaviour of use better, the present authors have developed a model VTSM which includes the effects of van der Walls interactions $(V W I)$ and three-body interactions $(T B I)$ in the frame work of both ions polarizable rigid shell model $(R S M)$. In this model second neighbour short range interactions have been considered to be effective upto the second neighbours.

\section{THEORY}

In addition to the Coulomb attraction force, there exists another attraction between the closed shell atoms. The nature of this attraction is different and owes its origin to the correlations of the electron motions in different atoms. The electrons of each atom shift with respect to the nucleus in the presence of other atoms and consequently an atom becomes an electric dipole. The instantaneous dipole moment of a closed shell atom induces a dipole moment on a similar atom and the interactions energy thus arising is known as the van der Waals interaction (VWI) potential. Now including the effects of van der Waals interactions and three-body interactions in the frame work of both ions polarizable rigid shell model (RSM), the general formalism of present model (VTSM) can be derived from the crystal potential whose relevant expression per unit cell is given by

$$
\phi=\phi^{C}+\phi^{R}+\phi^{T B I}+\phi^{V W I}
$$

where, first term $\phi^{C}$ is Coulomb intersection potential and is long-range in nature. Second term $\phi^{R}$ is short range overlap repulsion potential. Third term $\phi^{T B I}$ is three body interactions potential and the last term $\phi^{V W I}$ is van der Waals interaction potential and owes its origin to the correlations of the electron motions in different atoms. 
Using the crystal expression (1) and introducing the effect of $V W I$ and $T B I$, the secular determinant:

$$
\left|\underline{D}(\bar{q})-W^{2} \underline{m} \underline{I}\right|=0
$$

For the frequency determination here $\underline{D}(q)$ is the $(6 \times 6)$ dynamical matrix given by

$$
\begin{aligned}
\underline{\mathrm{D}}(\overline{\mathrm{q}})=\left(\underline{\mathrm{R}}+\underline{\mathrm{Z}}_{\mathrm{m}} \underline{\mathrm{C}}^{\prime} \underline{\mathrm{Z}}_{\mathrm{m}}\right)-\left(\underline{\mathrm{T}}+\underline{\mathrm{Z}}_{\mathrm{m}} \underline{\mathrm{C}}^{\prime} \underline{\mathrm{Y}}_{\mathrm{m}}\right) \\
\quad \times\left(\underline{S}+\underline{K}+\underline{Y}_{m} \underline{C}^{\prime} \underline{Y}_{m}\right)^{-1} \times\left(\underline{T}^{T}+\underline{Y}_{m} \underline{C}^{\prime} \underline{Z}_{m}\right)
\end{aligned}
$$

The number of adjustable parameters have been largely reduced by considering all the short-range interactions to act only through the shells. This assumptions leads to $\underline{R}=\underline{T}=\underline{S} \cdot \underline{C^{\prime}}$ is the modified long-range interaction matrix given by

$$
\underline{C^{\prime}}=\underline{C}+\left(\underline{Z}_{m}^{-2} 2 r_{0} f_{0}^{\prime}\right) \underline{r}
$$

and the expressions derived for elastic constants from eqn. (4) corresponding to present model are obtained as

$$
\begin{aligned}
\frac{4 r_{0}^{4}}{e^{2}} C_{11} & =\left[-5.112 \xi^{2}+A_{12}+\frac{1}{2}\left(A_{11}+A_{22}\right)+\frac{1}{2}\left(B_{11}+B_{22}\right)+9.3204 \xi^{\prime 2}\right] \\
\frac{4 r_{0}^{4}}{e^{2}} C_{12} & =\left[0.226 \xi^{2}-B_{12}+\frac{1}{4}\left(A_{11}+A_{22}\right)-\frac{5}{4}\left(B_{11}+B_{22}\right)+9.3204 \xi^{\prime 2}\right] \\
\frac{4 r_{0}^{4}}{e^{2}} C_{44} & =\left[2.556 \xi^{2}+B_{12}+\frac{1}{4}\left(A_{11}+A_{22}\right)+\frac{3}{4}\left(B_{11}+B_{22}\right)\right]
\end{aligned}
$$

In view of the equilibrium condition $\left.[d \phi / d r)_{0}=0\right]$

or $B_{11}+B_{22}+B_{12}=-1.165 \xi^{2}$

where

$$
\xi= \pm \sqrt{\left\{1+\frac{12 f(r)}{z}\right\}_{0}}, \quad \xi= \pm \sqrt{\left\{\frac{r}{z} \cdot \frac{d f}{d r}\right\}_{0}}
$$

and

$$
Z_{m}=Z \xi
$$

The term $f(r)$ is a function dependent on the overlap integrals of the electron wave functions and the subscript zero on the brackets indicates the equilibrium values of the quantities inside. The expression (7) can now be written in the form

$$
\frac{4 r_{0}^{4}}{e^{2}} C_{44}=\left[1.391 \xi^{2}+\frac{A_{2}-B_{2}}{4}\right]
$$

As $C_{44}$ is a very small quantity in the present case, the calculated value of $\left[\left(4 r_{0}^{4} / e^{2}\right) C_{44}-1.391 \xi^{2}\right]$ is found to be a negative quantity so that $\left(\mathrm{A}_{2}-\mathrm{B}_{2}\right)$ is negative. This suggests that these terms belong to an attractive interaction and possibly arise due to van der Waals energy. The van der Waals energy converges fast but the overlap repulsion converges much faster. Therefore the overlap repulsion is effective only upto the first neighbour and the van der Waals attraction upto the second neighbour.

If we consider the second neighbour dipole-dipole van der Waals interaction energy, then it is expressed as

$$
\phi_{d d}^{V W I}(r)=-S_{v}\left|\frac{C_{++}+C_{--}}{6 r^{6}}\right|=\phi^{v}(r)
$$

where $S_{v}$ is a lattice sum and the constants $C_{++}$and $C_{--}$are the van der Waals coefficients corresponding to the positive-positive and negative-negative ion pairs, respectively.

By solving the secular equation (2) along ( $(\mathrm{g}, 0,0)$ direction and subjecting the short and long-range coupling coefficients to the long wavelength limit $\vec{q} \rightarrow 0$, two distinct optical vibration frequencies are obtained as

$$
\left(\mu W_{L}^{2}\right)_{q=0}=R_{0}^{\prime}+\frac{\left(\mathrm{Z}^{\prime} e\right)^{2}}{v f_{L}} \cdot \frac{8 \pi}{3}\left(\xi^{2}+6 \xi^{\prime 2}\right)
$$




$$
\left(\mu W_{T}^{2}\right)_{q=0}=R_{0}^{\prime}-\frac{\left(\mathrm{Z}^{\prime} e\right)^{2}}{v f_{T}} \cdot \frac{4 \pi}{3} \xi^{2}
$$

where the abbreviations stand for

$$
\begin{aligned}
& R_{0}^{\prime}=R_{0}-e^{2}\left(\frac{d_{1}^{2}}{\alpha_{1}}+\frac{d_{2}^{2}}{\alpha_{2}}\right) Z^{\prime}=Z_{m}+d_{1}-d_{2} \\
& f_{\mathrm{L}}=1+\frac{\left(\alpha_{1}+\alpha_{2}\right)}{V} \cdot \frac{8 \pi}{3}\left(Z_{m}^{2}+6 \xi^{\prime 2}\right) \\
& f_{T}=1-\left(\frac{\alpha_{1}+\alpha_{2}}{v}\right) \cdot \frac{4 \pi}{3} \xi^{2}
\end{aligned}
$$

and

$$
\alpha=\alpha_{1}+\alpha_{2}
$$

and $v\left(=2 r_{0}^{3}\right)$ is the volume of unit cell in rock salt structure.

Also $\alpha_{1}, \alpha_{2}$ are the electronic polarizabilities and $d_{1}, d_{2}$ are the distortion polarizabilities of positive and negative ions, respectively.

\section{RESULT, DISCUSSION AND CONCLUSION}

The Fourteen parameters of our model VTSM have been calculated using above expressions (5-16) and presented along with input data in Table 1 . These model parameters have been used to compute the phonon dispersion curves of SrO. The calculated phonon dispersion curves of $\mathrm{SrO}$ have been displayed with experimental data [4] in Figure 1. The agreement between our computed phonon spectra and experimental data is excellent in Table 2. Our model VTSM has successfully explained the phonon anomalies even along $(\mathrm{q}, 0,0)$ and (q,q,q) directions. From figure 1 and Table 2 it is clear that VTSM, improves result of TSM by $8.3 \%$ along $L O(x), 5.7 \%$ along $T O(x), 4.53 \%$ along $L A(x), 1.3 \%$ along $T A(x), 4.36 \%$ along $L O(L), 3.98 \%$, along $T O(L)$, $13.56 \%$ along $L A(L)$ and $0.33 \%$ along $T A(L)$ the deviation between theory and experimental due to TSM is maximum $13.98 \%$ along $L A(L)$ while due VTSM the deviation is maximum $1.04 \%$ along $T A(x)$. However, the predictions of PDC for SrO by using VTSM may be considered more satisfactory than those from other models $[1-4]$.

The adequacies of VTSM have been further tested by studying specific heat variations and two phonon IR/Raman spectra. For this purpose we have computed the specific heats from the phonon spectra and plotted Debye temperature $\Theta_{D}$ the temperature $T$. It has been presented along with measured data in Figure 2. Our results are in good agreement with measured data [20] and are generally better than by using BSM [4]. The small deviation at higher temperature might be mainly due to the anharmonicity involved in the lattice vibrations. As two phonon IR/Raman spectra are sensitive at higher frequency side for this we have employed the critical point analysis [10] to study these properties. A comparison of CDS peaks along with the observed Raman peaks Table 3 and observed IR peaks Table 4 and their assignments from present study has been shown in Figure 3. The basic aim of the study of two phonon IR/Raman scattering spectra is to correlate the neutron and optical experimental data for $\mathrm{SrO}$. We have also investigated the anharmonic properties of $\mathrm{SrO}$ by using VTSM Table (5-6). This includes the predictions of third and fourth order elastic constants and the pressure derivatives of $S O E$ and $T O E$ constants. The expressions for these elastic constants and pressure derivatives of second order elastic constants derived by us correspond to three-body lattice energy are similar to those derived by Puri, Verma and Garg [23] for $\mathrm{NaCl}$ structure in the framework of TSM. The third order and fourth order elastic constants. Since no experimental values on these properties have been reported so far, we are unable to comment on them but our results will help the experimental workers to analyze their data in future. This study gets strong support from recent publications of our research group [24-43]. To conclude we can say that the present model SOE VTSM has successfully explained the phonon properties which include phonon dispersion curves variations of $\Theta_{D}$ with temperature $T$ and combined density of states. Our extensive study on anharmonic properties is to provide physical insight into the nature of binding forces between the constituents of $\mathrm{SrO}$. The induction of van der Waals interactions essential in the study of lattice dynamics of ionic crystals. 
Effect of van der Waals and three body interactions on the lattice dynamics of Ionic crystals: an application to $\mathrm{SrO}$

\section{FIGURE AND TABLES}

Table 1: Input data and model parameters for $\operatorname{SrO}\left[C_{i j}\right.$ and B (in $10^{12} \mathrm{dyne} / \mathrm{cm}^{2}$ ), $v$ (in THz), $r_{0}\left(\right.$ in $\left.10^{-8} \mathrm{~cm}\right), \alpha_{i}\left(\right.$ in $\left.10^{-24} \mathrm{~cm}^{3}\right), \mathrm{b}\left(\right.$ in $\left.10^{-12} \mathrm{erg}\right), \rho$ (in $\left.\left.10^{-8} \mathrm{~cm}\right),\right]$

\begin{tabular}{|c|c|c|c|c|}
\hline \multicolumn{3}{|c|}{ Input Data } & \multicolumn{2}{c|}{ Model Parameters } \\
\hline Properties & Values & Ref. & Parameters & Values \\
\hline $\mathrm{C}_{11}$ & 17.33 & {$[15]$} & $b$ & 0.792 \\
\hline $\mathrm{C}_{12}$ & 4.53 & {$[15]$} & $\rho$ & 0.68 \\
\hline $\mathrm{C}_{44}$ & 5.60 & {$[15]$} & $f\left(r_{0}\right)$ & -0.348 \\
\hline $\mathrm{B}$ & 6.87 & {$[15]$} & $r_{0} f^{\prime}\left(r_{0}\right)$ & -0.060942 \\
\hline$r_{0}$ & 2.580 & {$[16]$} & $\mathrm{A}_{12}$ & 20.6045 \\
\hline$v_{\mathrm{LO}}(\Gamma)$ & 14.40 & {$[4]$} & $\mathrm{B}_{12}$ & 12.38929 \\
\hline$v_{\mathrm{TO}}(\Gamma)$ & 14.40 & {$[4]$} & $\mathrm{A}_{11}$ & -1.82429 \\
\hline$v_{\mathrm{LO}}(\mathrm{L})$ & 13.8 & {$[4]$} & $\mathrm{B}_{11}$ & -4.42713 \\
\hline$v_{\mathrm{TO}}(\mathrm{L})$ & 8.28 & {$[4]$} & $\mathrm{A}_{22}$ & 5.14596 \\
\hline$v_{\mathrm{LA}}(\mathrm{L})$ & 7.08 & {$[4]$} & $\mathrm{B}_{22}$ & -8.87364 \\
\hline$v_{\mathrm{TA}}(\mathrm{L})$ & 3.04 & {$[4]$} & $\mathrm{d}_{1}$ & 0.4062674 \\
\hline$\alpha_{1}$ & 1.60 & {$[17]$} & $\mathrm{d}_{2}$ & 0.1868492 \\
\hline$\alpha_{2}$ & 2.095 & {$[17]$} & $\mathrm{Y}_{1}$ & -4.87299 \\
\hline$\varepsilon_{0}$ & 8.79 & {$[17]$} & $\mathrm{Y}_{2}$ & -5.5796537 \\
\hline
\end{tabular}

Table 2. Comparison of frequencies from various sources (X and $\mathrm{L}$ points) for $\mathrm{SrO}$

\begin{tabular}{|c|c|c|c|c|c|c|c|c|c|}
\hline \multirow[t]{2}{*}{ SrO } & & \multirow[t]{2}{*}{ Expt. [4] } & \multicolumn{3}{|c|}{ TSM [13] } & \multicolumn{3}{|c|}{ VTSM (Present study) } & \multirow{2}{*}{$\begin{array}{c}\% \\
\text { improvemen } \\
\text { (a-b) }\end{array}$} \\
\hline & & & Value & $\begin{array}{c} \pm \\
\text { deviation }\end{array}$ & $\%(\mathbf{a})$ & Value & $\begin{array}{c} \pm \\
\text { deviation }\end{array}$ & $\%(b)$ & \\
\hline \multirow[t]{4}{*}{$X(100)$} & $\begin{array}{c}\mathrm{LO} \\
(\mathrm{THz})\end{array}$ & 9.84 & 9.01 & 0.83 & 8.4 & 9.85 & 0.01 & 0.10 & 8.3 \\
\hline & $\begin{array}{c}\mathrm{TO} \\
(\mathrm{THz})\end{array}$ & 7.41 & 6.99 & 0.42 & 5.6 & 7.45 & 0.04 & 0.53 & 5.07 \\
\hline & $\begin{array}{c}\text { LA } \\
(\mathrm{THz})\end{array}$ & 5.88 & 5.59 & 0.29 & 4.93 & 5.85 & 0.03 & 0.51 & 4.53 \\
\hline & $\begin{array}{c}\mathrm{TA} \\
(\mathrm{THz}) \\
\end{array}$ & 3.84 & 3.75 & 0.09 & 2.34 & 3.80 & 0.04 & 1.04 & 1.30 \\
\hline \multirow[t]{4}{*}{$\begin{array}{c}\mathrm{L} \\
(.5 .5 .5)\end{array}$} & $\begin{array}{c}\mathrm{LO} \\
(\mathrm{THz})\end{array}$ & 12.84 & 13.46 & 0.62 & 4.82 & 12.90 & 0.06 & 0.46 & 4.36 \\
\hline & $\begin{array}{c}\mathrm{TO} \\
(\mathrm{THz})\end{array}$ & 8.28 & 8.64 & 0.36 & 4.34 & 8.25 & 0.03 & 0.36 & 3.98 \\
\hline & $\begin{array}{c}\text { LA } \\
(\mathrm{THz})\end{array}$ & 7.08 & 6.89 & 0.99 & 13.98 & 7.05 & 0.03 & 0.42 & 13.56 \\
\hline & $\begin{array}{c}\mathrm{TA} \\
(\mathrm{THz})\end{array}$ & 3.04 & 3.06 & 0.02 & 0.65 & 3.05 & 0.01 & 0.32 & 0.33 \\
\hline
\end{tabular}


Effect of van der Waals and three body interactions on the lattice dynamics of Ionic crystals: an application to $\mathrm{SrO}$

Table 3. Comparison of CDS peaks with the observed peaks of second order Raman scattering spectra for $\mathrm{SrO}$

\begin{tabular}{|c|c|c|c|}
\hline \multirow{2}{*}{$\begin{array}{l}\text { Observed Raman } \\
\text { Peaks }\left(\mathbf{c m}^{-1}\right)[21]\end{array}$} & \multicolumn{3}{|c|}{ Present Study } \\
\hline & CDS Peaks $\left(\mathrm{cm}^{-1}\right)$ & Assignment & Value $\left(\mathrm{cm}^{-1}\right)$ \\
\hline - & 106 & - & - \\
\hline- & 141 & - & - \\
\hline - & 193 & $2 \mathrm{TA}(\Delta)$ & 204 \\
\hline 350 & 342 & $\mathrm{LA}+\mathrm{TA}(\mathrm{L})$ & 337 \\
\hline - & 368 & $\mathrm{TO}+\mathrm{TA}(\mathrm{x})$ & 375 \\
\hline- & 412 & $2 \mathrm{LA}(\mathrm{x})$ & 390 \\
\hline 450 & 465 & $\mathrm{TO}+\mathrm{LA}(\Delta)$ & 413 \\
\hline- & - & $\mathrm{TO}+\mathrm{LA}(\mathrm{x})$ & 443 \\
\hline- & - & $\mathrm{LO}+\mathrm{TA}(\mathrm{x})$ & 455 \\
\hline- & - & $2 \mathrm{TO}(\mathrm{x})$ & 496 \\
\hline- & - & $\mathrm{LO}+\mathrm{LA}(\mathrm{x})$ & 523 \\
\hline- & 543 & $2 \mathrm{TO}(\mathrm{L})$ & 550 \\
\hline- & - & $\mathrm{LO}+\mathrm{TO}(\mathrm{x})$ & 576 \\
\hline 600 & 603 & $\mathrm{LO}+\mathrm{TO}(\mathrm{x})$ & 596 \\
\hline- & - & $2 \mathrm{LO}(\mathrm{x})$ & 656 \\
\hline- & 693 & $\mathrm{LO}+\mathrm{TO}(\mathrm{L})$ & 705 \\
\hline 750 & 760 & - & - \\
\hline 960 & - & - & - \\
\hline
\end{tabular}


Effect of van der Waals and three body interactions on the lattice dynamics of Ionic crystals: an application to $\mathrm{SrO}$

Table 4. Comparison of CDS peaks with the observed peaks of second order IR spectra for $\mathrm{SrO}$

\begin{tabular}{|c|c|c|c|}
\hline \multirow{2}{*}{$\begin{array}{l}\text { Observed IR Peaks } \\
\qquad\left(\mathrm{cm}^{-1}\right)[22]\end{array}$} & \multicolumn{3}{|c|}{ Present Study } \\
\hline & CDS Peaks $\left(\mathrm{cm}^{-1}\right)$ & Assignment & Value $\left(\mathrm{cm}^{-1}\right)$ \\
\hline - & 106 & - & - \\
\hline- & 141 & - & - \\
\hline- & 193 & $2 \mathrm{TA}(\Delta)$ & 204 \\
\hline- & 255 & - & - \\
\hline- & 342 & $\mathrm{TO}+\mathrm{TA}(\Delta)$ & 377 \\
\hline 387 & 368 & $\mathrm{TO}+\mathrm{TA}(\mathrm{L})$ & 377 \\
\hline - & 412 & $\mathrm{TO}+\mathrm{LA}(\Delta)$ & 413 \\
\hline 470 & 465 & $2 \mathrm{TO}(\Delta)$ & 470 \\
\hline 503 & - & $\mathrm{LO}+\mathrm{LA}(\mathrm{L})$ & 507 \\
\hline 510 & - & $\mathrm{LO}+\mathrm{TA}(\Delta)$ & 510 \\
\hline 537 & 543 & $\mathrm{LO}+\mathrm{TA}(\mathrm{L})$ & 532 \\
\hline- & 603 & - & - \\
\hline- & 693 & $\mathrm{LO}+\mathrm{LA}(\mathrm{L})$ & 665 \\
\hline 813 & 790 & - & - \\
\hline
\end{tabular}

Table 5. Third and fourth order elastic constants (in units $10^{12} \mathrm{dyn} / \mathrm{cm}^{2}$ ) for SrO

\begin{tabular}{|c|c|c|c|}
\hline Property & Values & Property & Values \\
\hline$C_{111}$ & 89.4456 & $C_{1122}$ & -4.10844 \\
\hline$C_{112}$ & 0.4592 & $C_{1266}$ & 0.43587 \\
\hline$C_{166}$ & -0.3157 & $C_{4444}$ & 1.57041 \\
\hline$C_{123}$ & 0.0650 & $C_{1123}$ & 0.39543 \\
\hline$C_{144}$ & 0.0722 & $C_{1144}$ & 0.32455 \\
\hline$C_{456}$ & 0.0848 & $C_{1244}$ & -2.60823 \\
\hline$C_{1111}$ & 132.5991 & $C_{1456}$ & 0.20843 \\
\hline$C_{1112}$ & 2.5507 & $C_{4456}$ & 0.76095 \\
\hline$C_{1166}$ & 1.0226 & & \\
\hline
\end{tabular}


Effect of van der Waals and three body interactions on the lattice dynamics of Ionic crystals: an application to $\mathrm{SrO}$

Table 6. Values of pressure derivatives of SOE and TOE constants for SrO

\begin{tabular}{|c|c|}
\hline Property & Values \\
\hline$d k^{\prime} / d P$ & 8.50395 \\
\hline$d s^{\prime} / d P$ & 5.73742 \\
\hline$d c_{44}^{\prime} / d P$ & 8.33855 \\
\hline$d c_{111}^{\prime} / d P$ & 33.68018 \\
\hline$d c_{112}^{\prime} / d P$ & 0.10896 \\
\hline$d c_{166}^{\prime} / d P$ & 1.41868 \\
\hline$d c_{123}^{\prime} / d P$ & 0.81510 \\
\hline$d c_{144}^{\prime} / d P$ & 1.39540 \\
\hline$d c_{456}^{\prime} / d P$ & 1.57249 \\
\hline
\end{tabular}

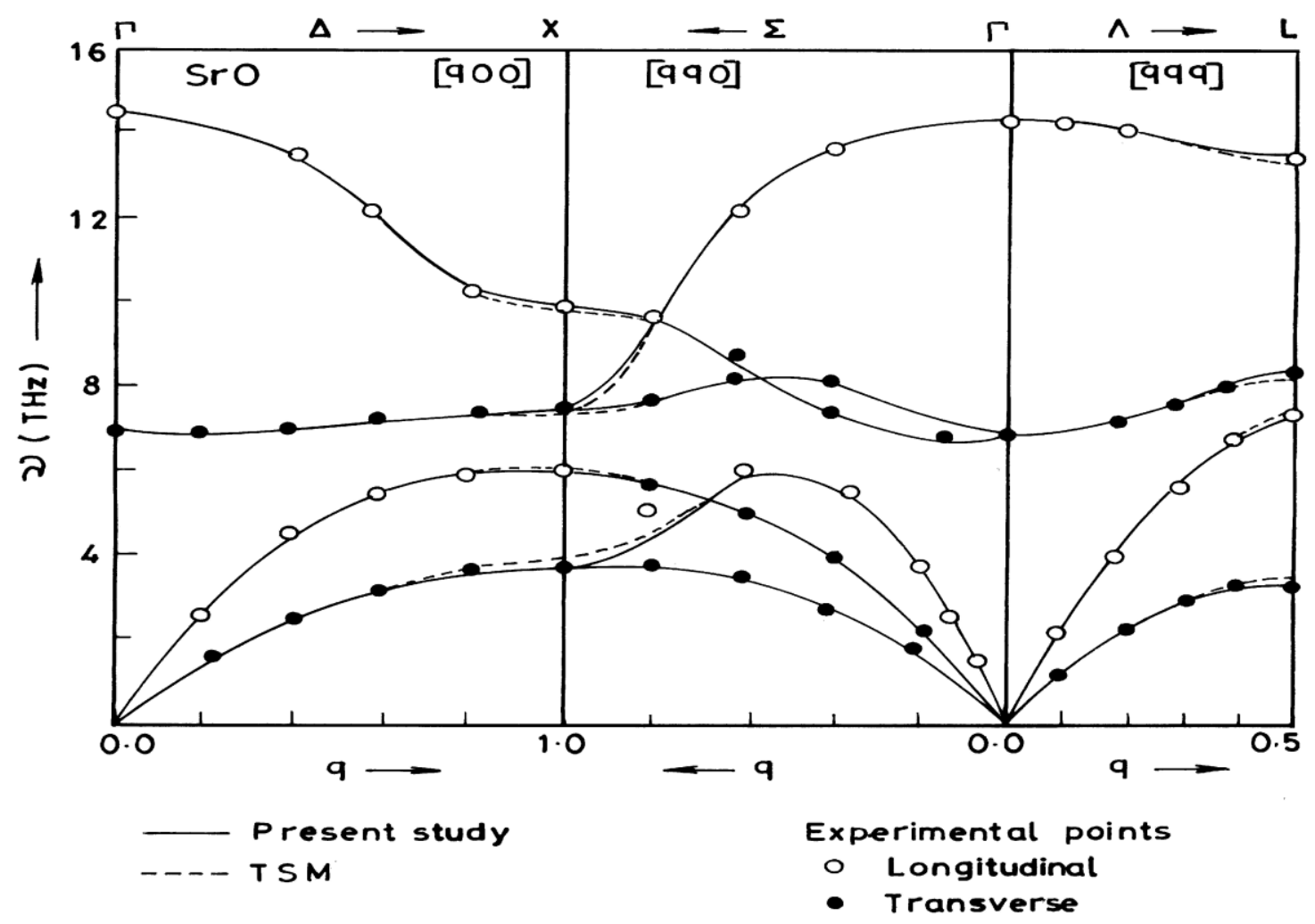

Figure 1: Phonon Dispersion Curve for SrO. 


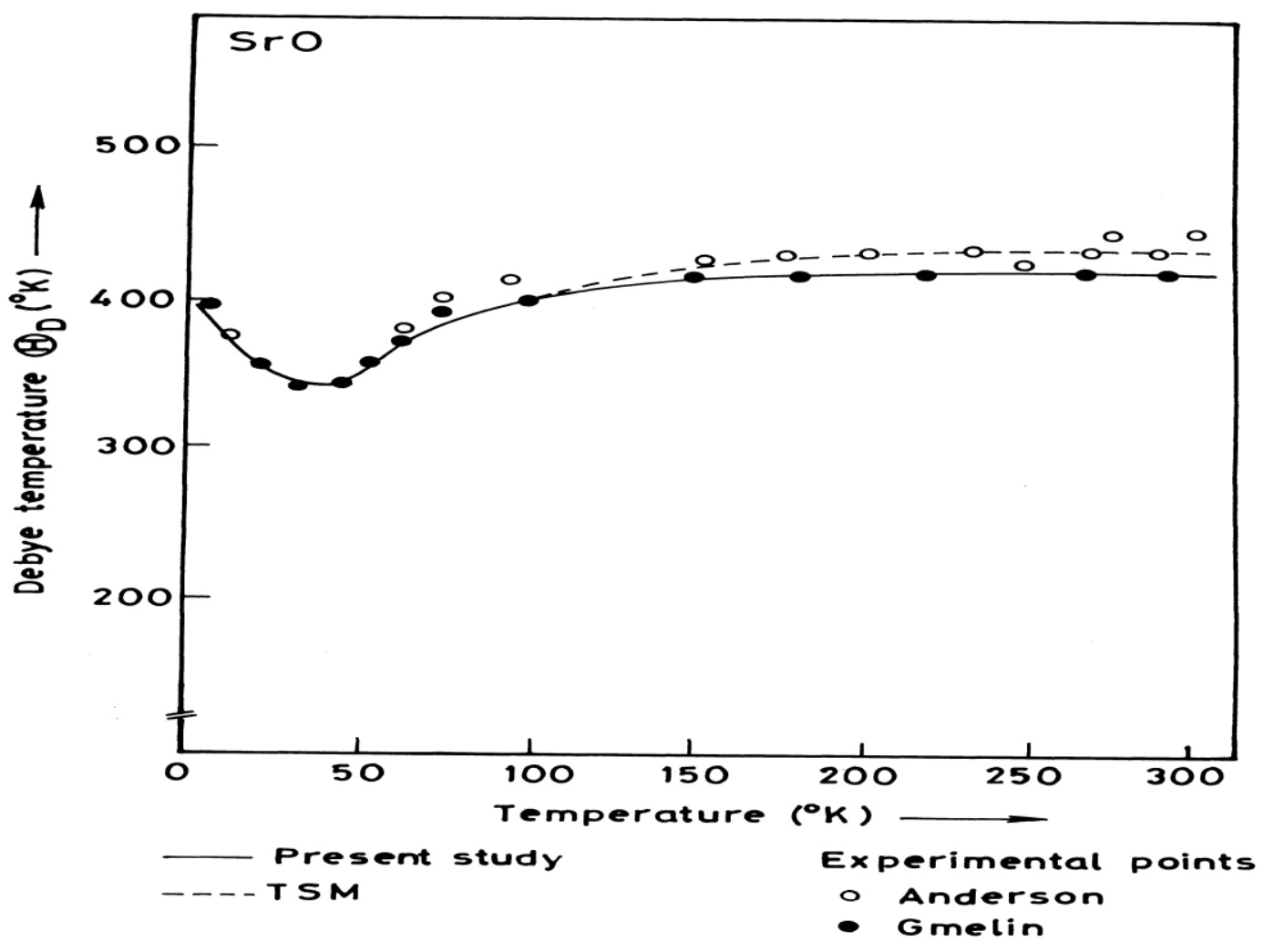

Figure 2: Combined density States (Two phonon) Curve for SrO.

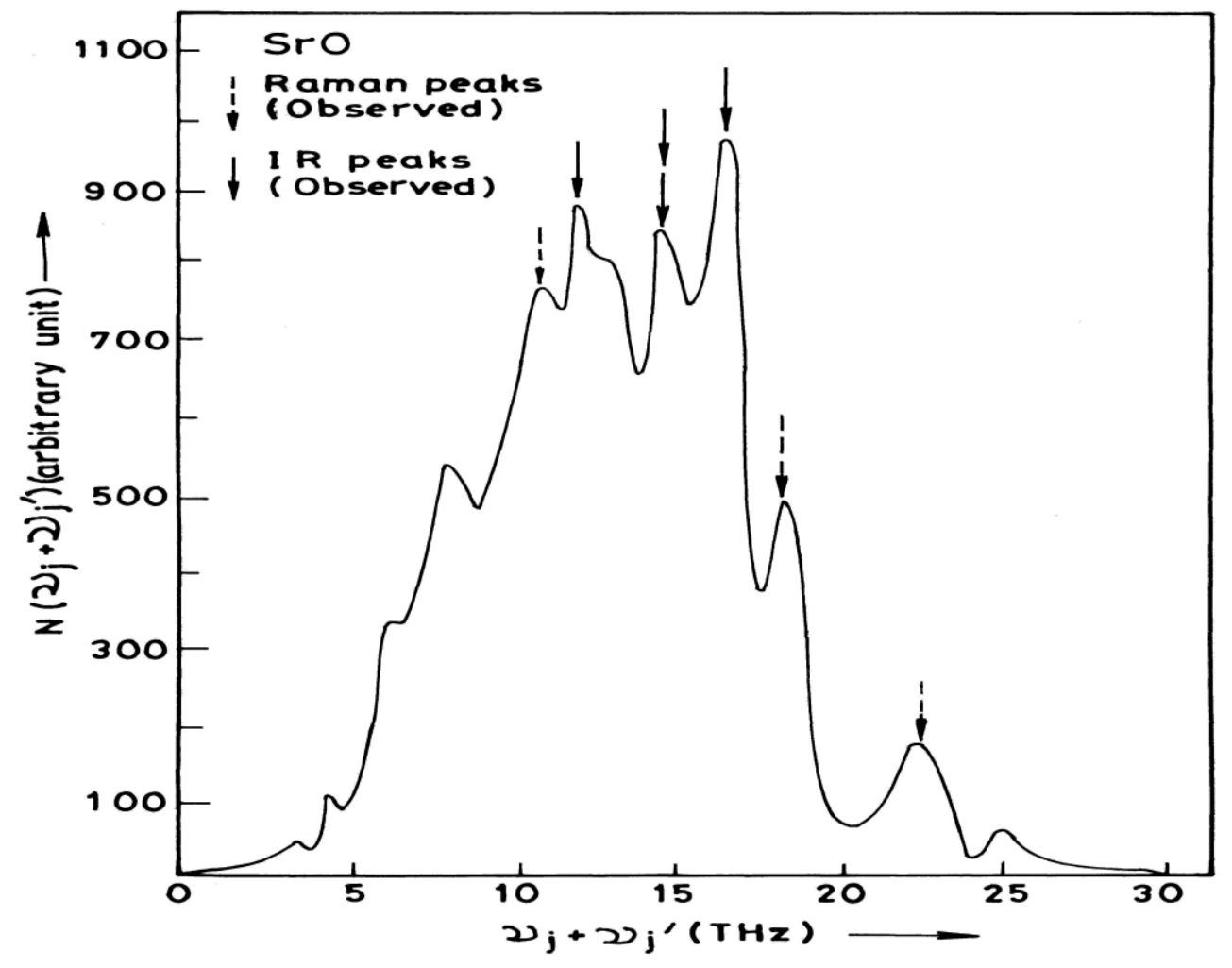

Figure 3: Debye Temperature Variation Curve for SrO. 


\section{ACKNOWLEDGEMENTS}

The authors are thankful to Prof. K.P.Mishra, VC and Dr. S.C. Tiwari, Pro. V.C., NGBU, Allahabad (India) for providing the necessary facilties. We are also thankful to Computer Center, BHU, Varanasi, India for providing computational assistance.

\section{REFERENCES}

[1]. Kellermann E.W., Phil. Tons. Roy. Soc. A238, 513 (1940) and Proc. Roy. Soc. A178, 17 (1941).

[2]. Woods A.D.B., Cochran W. and Brock House B.N., Phy. Rev. 119, 980 (1960)

[3]. V. Nussleen and U. Schroder, Phys. Stat. Sol. 21, 309 (1967).

[4]. Basu A.H. and Sengupta S., Phys. Stat. Sol. 29, 367 (1968).

[5]. Sangster M.L.J., Peckhahm G. and Saunderson D.H., J. Phys. C3, 1026 (1970).

[6]. Vijayraghvan P.R., Proc. Internet. Conf. on Phonon. Rejms, France (26-28) July, pp. 139 (1971) and data from Private Communication

[7]. Saunderson D.H. and Pekham G., J. Phys. C4, 2009 (1971)

[8]. Rieder K.H. and Migoni R. and Renker B., Phys. Rev. B12, 3374 (1975).

[9]. Chang S.S., Tompson C.W., Gurmen E. and Muhfestein L.D., J. Phys. Chem., Solids 36, 769 (1975).

[10]. Manson N.B., Phys. Rev. B4 (1971) 2645-2656.

[11]. Peckham G., Proc. Phys. Soc. Lond. A250 (1967) 70.

[12]. Ghosh A. and Basu A.N., Phys. Rev. B17, 4558 (1978).

[13]. Upadhyaya K.S. and Singh R.K., Phys. Rev., B6, 1589-1596 (1972).

[14]. Upadhyaya K.S. and Singh R.K., J. Phys. Chem. Sol. 35, 1175-1179 (1974).

[15]. Son R.R. and Bartels R.A. , J. Phys. Chem. Sol. 33, 814 (1972).

[16]. Upadhyaya K.S. and Pandey A.N., Phys. Stat. Sol.(b) 78, 351-353 (1977).

[17]. Willmott J.C., Proc. Phys. Soc. A63, 389 (1950).

[18]. Boswarah I.M. , Phy. Rev. B1, 1698 (1970).

[19]. Gemlin E., Z. Haturforsch, A24 1794 (1969).

[20]. Anderson A., J. Am. Chem. Soc. 57, 429 (1935).

[21]. Mon J.P., Private Communication

[22]. Jacobson J.L.and Nixon E.R., J. Physics Chem. Solids, 29, 967 (1969)

[23]. Puri D.S., Garg V.K. and Verma M.P., Phys. Stat. Sol.(b) 78, (1976) 113

[24]. Upadhyaya K.S., Upadhyay G.K. and Yadava M., J. Phys. Soc. Japan 70, 3, 901 (2001).

[25]. Upadhyaya K.S., Upadhyay G.K. and Pandey A.N. J. Phys. Chem. Sol. 63, 127 (2002).

[26]. Upadhyaya K.S., Yadav M. and Upadhyay G.K., Phys. Stat. Sol. B229, 1129 (2002).

[27]. Upadhyaya K.S., Pandey A.N., Pandey Atul and Dubey R.C., Latvian J. Phys. \& Tech. Sciences, N6, 12 (2004).

[28]. Upadhyaya K.S., Singh Ajai Kumar, Kumar Awanish, Pathak S.N. and Pandey Atul Pramana Jl. Physics, 64, 299 (2005).

[29]. Ojha P.K., Pratap Syamendra Singh and Upadhyaya K.S., Indian J. Pure Appl. Phys., Vol. 45 pp. $79-82$ (2007).

[30]. Pandey Atul, Pandey Amarnath and Upadhyaya K.S., Romanian Journal of Physics, Vol. 51, Nos. 3-4, 367 (2006).

[31]. Pandey Atul and Upadhyaya K.S., Lithuanian Journal of Phys. 46, 355 (2006).

[32]. Upadhyaya K.S., Pandey Atul and Srivastava D.M., Chinese Journal of Phys., Vol. 44, 127 (2006).

[33]. Tiwari S.K., Pandey L.K., Shukla L.J., Upadhyaya K.S., Physica Scripta, 80, 1 (2009).

[34]. Tiwari S.K., Shukla L.J. and Upadhyaya K.S., Pramana Jour. Of Phys. 74, 793 (2010)

[35]. Tiwari S.K., Singh R.K., Upadhyaya K.S., Philosophical Magzine, 90, 3531(2010).

[36]. Srivastava U.C., Pandey R.S., \& Upadhyaya K.S., International Journal of Physical sciences. Vol 5(7), pp 972-977 (2010).

[37]. Srivastava U.C \& Upadhyaya K S, Rapid Communication (OAM-RC), Vol 4, ISS 9, pp 1336-1341-Sept (2010).

[38]. Srivastava U.C.\& Upadhyaya K. S., Phys. Rev. and Research Int. -1 (1),16-28. (2011).

[39]. Mishra K.K, Upadhyay G.K. and.Upadhyaya K.S, Phys. Rev. and Research Int. 2(2), 91-106, 2012.

[40]. Mishra K.K and.Upadhyaya K.S, Jour. of Alloy and Compounds, Communicated (2012).

[41]. Mishra K.K.and Upadhyaya K.S., Int. Jourl. Engg. Research and Tech. 1(3), In press (2012).

[42]. Mishra K.K. and Upadhyaya K.S., Int. Jourl.Scientific Engg. Research, 3(8) In press (2012).

[43]. Mishra K.K., Dwiwedi B.P. and Upadhyaya K.S., Int. Jourl. Recent Scientific Research, Vol 3, In press (2012). 